\title{
Anatomic variation of the thoracic duct and absence of accessory hemiazygos and hemiazygos veins: case report
}

\author{
RODRIGUES, D. S. ${ }^{1 *}$, LEÃO, F. A. A. ${ }^{1}$, SIQUEIRA, S. L. ${ }^{1,2,3}$, \\ CARIM, L. L. C. ${ }^{1}$, LACERDA, G. C. ${ }^{1}$, SILVA, L. A. Q. ${ }^{1}$ and SILVA, A. T. ${ }^{1}$ \\ ${ }^{1}$ Faculdade de Ciências Médicas de Minas Gerais - FCMMG, \\ Alameda Ezequiel Dias, 275, Centro, CEP 30130-110, Belo Horizonte, MG, Brasil \\ ${ }^{2}$ Universidade Federal de Minas Gerais - UFMG, Av. Antônio Carlos, 6627, Pampulha, \\ CEP 31270-901, Belo Horizonte, MG, Brasil \\ ${ }^{3}$ Universidade Federal de Ouro Preto - UFOP, Ouro Preto, MG, Brasil \\ *E-mail: diegofcmmg@gmail.com
}

\begin{abstract}
The thoracic duct is a lymph vessel extending from the abdomen to the base of the neck where it drains to one of the large veins in the region. Many cases are described in the scientific literature, regarding anatomical variations of the thoracic duct, from its origin, path, until its end, and the vast majority intended to relate variations in the last part of the duct. The reports related to variations of its path are very scarce. In a male cadaver dissection in the anatomy laboratory of the Faculdade de Ciências Médicas of Minas Gerais (FCMMG), an anatomical variation of the position of the thoracic duct was found. The thoracic duct was presented to the left of the aorta and spine, from its entry in the aortic hiatus of the diaphragm and chest throughout its length. There were also anatomical variations of interest in the venous circulatory system, such as the absence of the veins: hemiazygos and accessory hemiazygos, and the different location of the azygos vein, which was located to the left of the aorta. These variations have no relation to each other. The study of this variation is important because the knowledge of variations in the thoracic duct path allows lower rates of trauma and iatrogenic lesions in thoracic surgery, with possible serious complications, such as a chylothorax.
\end{abstract}

Keywords: thoracic duct, hemiazygos, accessory hemiazygos, anatomical variation.

\section{Introduction}

In the lymphatic system, the thoracic duct is the main and largest vessel component, with approximately $3 \mathrm{~mm}$ caliber and approximate length between 38 and $45 \mathrm{~cm}$ from the upper abdomen to the base of the neck, where it opens into one of the large veins there present. It rises in the level of the second lumbar vertebra, on the right, and subsequently in relation to the abdominal aorta medially to the right pillar of the diaphragm from a dilatation called chyle cistern, which is formed by the junction of the lumbar and intestinal trunks (PEÑA and ZUNIGA, 2009); (GARDNER, GRAY and O'RAHILLY, 2008). Ascends in the posterior mediastinum, to the right of the aorta, between the aorta and vena ázigos (GARDNER, GRAY and O'RAHILLY, 2008); (MOORE, 2001); (GRAY, 2010). At the level of the fifth or sixth thoracic vertebra, the thoracic duct begins to shift to the left, crossing obliquely behind the esophagus. It goes up to the left of the esophagus passing behind the left subclavian artery and enters the neck (GARDNER, GRAY and O'RAHILLY, 2008). In the base of the neck, makes a loop and crosses the subclavian artery. After that it goes forward and descends, ending in the left jugular vein ${ }^{2}$, or other large vein in the region (PENA and ZUNIGA, 2009) (Figure 1).

From the point of view of embryogenesis, the lymphatic system is formed in the fifth week from the mesenchyme, after the development of the cardiovascular system. Initially, there are plexus of lymphatic capillaries accompanying venous trunks and, in some regions, they blend, giving rise to bags that formed the lymphatic vessels and then, directed to different regions of the body (PEÑA and ZUNIGA, 2009).

In the embryo, six primary lymph sacs are formed: two jugular veins in the union of the subclavian veins with the anterior cardiac veins; two iliac in the union of the internal iliac veins with the posterior cardinal veins, one retro peritoneal near the root of the mesentery, and the chyle cistern from behind (or beside) the retroperitoneal bag. From the complex capillary plexus that appears around the chest aorta and communicates the chyle cistern with both bags jugular, origins the thoracic ducts joined by numerous transverse anastomoses. The inferior part of the left thoracic duct disappears, whilst the right thoracic duct, the anastomosis and the cranial portion of the left thoracic duct form the thoracic duct (PENAA and ZUNIGA, 2009).

There is currently a small volume of publications worldwide in the field of anatomical variations related to the thoracic duct. The vast majority of these studies focus preferentially in variations associated with the thoracic duct confluence.

There are not reports in the ascendance of the duct to the left of the spine throughout its journey associated with the absence of accessory hemiazygos and hemiazygos veins.

The study of the variation in which the thoracic duct ascends towards the left compared to the azygos vein and the absence of veins hemiazygos and hemiazygos accessory is relevant to the risk of injury during thoracic surgeries, especially in the lower portion, wherein the duct is in a different position than expected. 


\section{Case Report}

The anatomical study is based on a dissection of one corpse in the Laboratory of Human Anatomy Department Morphophysiology of the Faculdade de Ciências Médicas de Minas Gerais in 2010, when it was found the anatomical variation to be described. The corpse studied was a male ethnic mixed race, without clinical history and with the cause of death unknown. The dissection method is based on descriptions given by Testut, Jacob and Billet (1921). The literature review was done based on anatomy textbooks and international scientific papers related to the theme.

During the dissection for the study of the chest, a rarely described anatomical variation was observed. Pulling the right lung out of the chest and dissecting the posterior region of the thorax, anterior to the left column and the descendent thoracic part of the aorta, it was noted the absence of the hemiazygos and accessory hemiazygos veins (Figure 2). It was

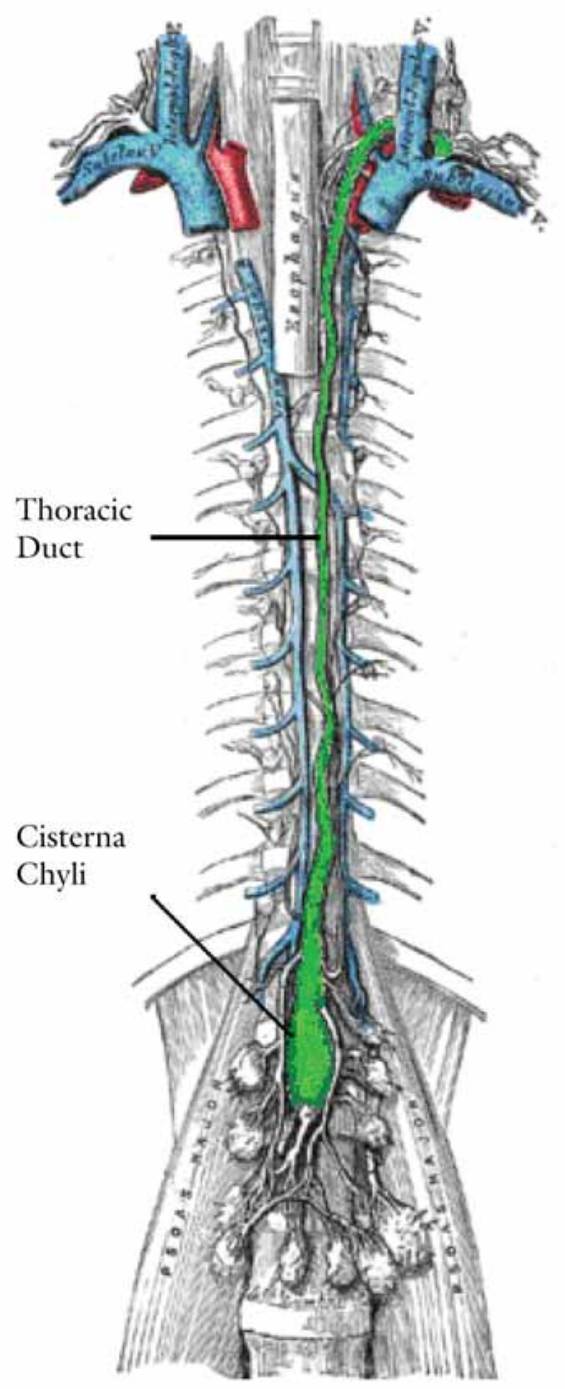

Figure 1. Normal anatomical position of the thoracic duct: between the azygos and hemiazygos veins, in the lower portion, and crossing to the left side of the body upwards, emptying into the venous system (GRAY, 2010). also observed the presence of the thoracic duct located on the left side of the aorta and the spine, all the way from its entry, in the aortic hiatus of the diaphragm, to its ending (Figure 3). The position of the thoracic duct in the posterior mediastinum, from the 5 th thoracic vertebrae, was equal to the traditional description found in the literature (Figure 4), where it expects to find that path after crossing, obliquely, the duct, from right to left, in the level of the vertebrae (GARDNER, GRAY and O'RAHILLY, 2008); (MOORE, 2001); (GRAY, 2010); (SKANDALAKIS, SKANDALAKIS and SKANDALAKIS, 2007). The duct ascended in the posterior mediastinum, on the left side of the esophagus, and penetrated into the neck, forming an arc, and finally ending in the left internal jugular vein, as it is normally described (GARDNER, GRAY and O'RAHILLY, 2008); (MOORE, 2001); (GRAY, 2010); (SKANDALAKIS, SKANDALAKIS and SKANDALAKIS, 2007). The azygos vein was dissected to the left of the aorta, in an unusual position, since, traditionally, this vein is located to the right (PENA and ZUNIGA, 2009); (GARDNER, GRAY and O'RAHILLY, 2008); (MOORE, 2001); (GRAY, 2010); (SKANDALAKIS, SKANDALAKIS and SKANDALAKIS, 2007); (KAUR, JAIN, DHALL et al., 2012).

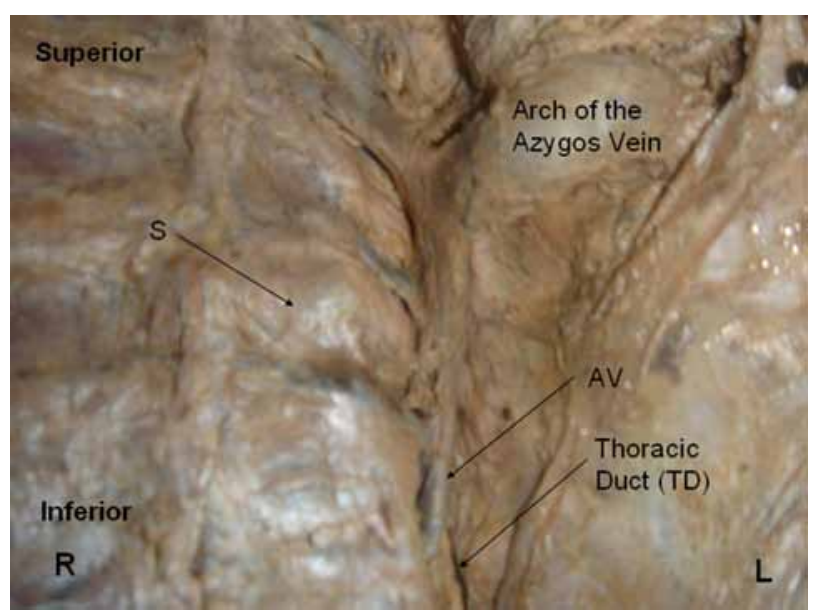

Figure 2. Thoracic duct (TD) covered almost completely by the azygos vein $(\mathrm{AV})$ to the left of the spine $(\mathrm{S})$. This image shows the presence of two anomalies: absence of hemiazygos and accessory hemiazygos veins along with thoracic duct on the left side of the spine (troughout the duct path).

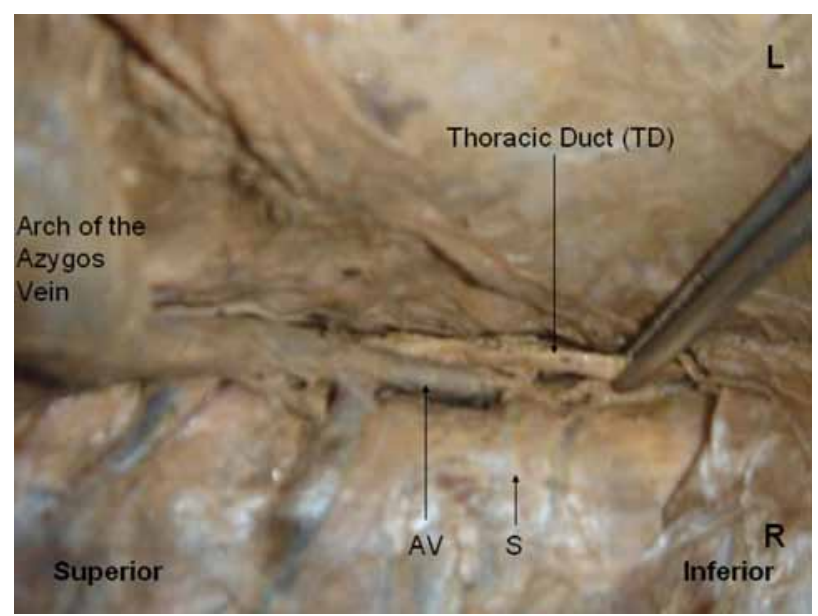

Figure 3. Thoracic duct pulled to the right, showing its position on the left side of the azygos vein (AV). 


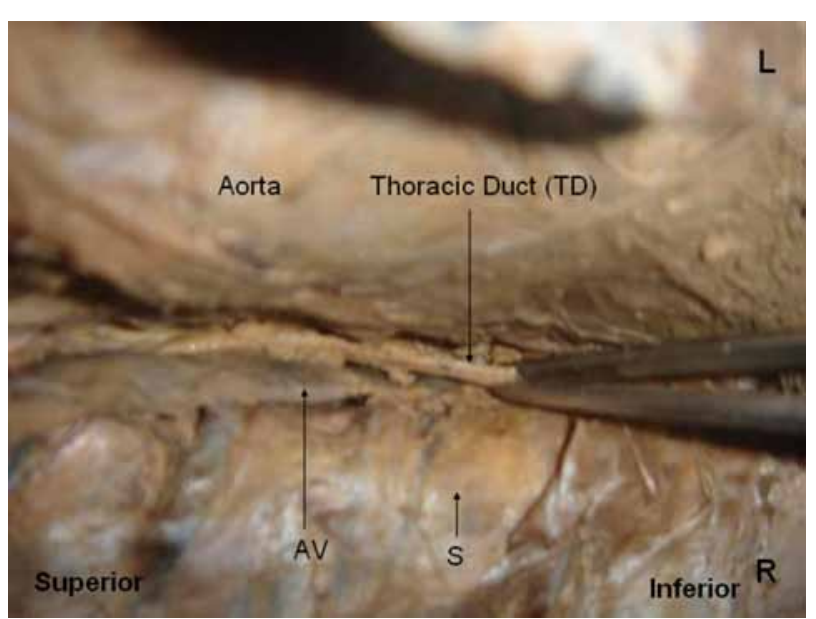

Figure 4. Thoracic duct exposed by traction on the left side of the azygos vein $(\mathrm{AV})$. Note that the only part to the right is the portion pulled and all the rest being located to the left of the azygos vein and the spine.

\section{Discussion}

In surgery, the anatomical knowledge of possible variations may have a particular relevance preventing structures this from being damaged.

Regarding the thoracic duct injury, a consequence may be the chylothorax. Chylothorax can be divided, according to its cause, in congenital, traumatic or neoplastic cause or multiple causes. Among the traumatic ones, surgical procedures with a thoracic approach may eventually lead to the injury of the thoracic duct, having the chylothorax as a consequence. The postoperative chylothorax occurs in less than $1 \%$ of thoracic surgery, with a prevalence of $0.5 \%$ to $2 \%$ and can cause nutritional deficiencies, respiratory system involvement, imunossupression and dehydration (PÊGO-FERNANDES, JATENE, TOKUNAGA et al., 2003).

Because of that, the publications related to anatomical variations of the thoracic duct are so important. However, there is very small volume of publications worldwide in the field of anatomical variations related to the thoracic duct, particularly regarding to changes in its trajectory.

Finally, it could not be founded cases in the literature demonstrating the ascendancy of the duct to the left of the spine all the way throughout its path associated with the absence of accessory hemiazygos and hemiazygos veins.

\section{References}

GARDNER, E., GRAY, DJ. and O'RAHILLY, R. Anatomia: estudo regional do corpo humano. 4 ed. Rio de Janeiro: Guanabara Koogan, 2008. 815 p.

GRAY, H. Anatomia: a base anatômica da prática clínica. 40 ed. Rio de Janeiro: Elsevier, 2010. 1584 p.

KAUR, D., JAIN, M., DHALL, U. and SINGH, K. An unusual course of the thoracic duct in relation to the vertebral vessels. Singapore Medical Journal, 2012, vol. 53, n. 1, p. el-e2. PMid:22252190.

MOORE, K. Anatomia orientada para clínica. 4. ed. Rio de Janeiro: Guanabara Koogan, 2001. 948 p.

PÊGO-FERNANDES, PM., JATENE, FB., TOKUNAGA, CC., SIMÃO, DT., BEIRUTTY, R., IWAHASHI, ER. and OLIVEIRA, SA. Ligadura do ducto torácico para o tratamento de quilotórax em cardiopatas. Arquivos Brasileiros de Cardiologia, 2003, vol. 81, n. 3, p. 309-317 PMid:14569375.

PEÑA, E. and ZUNIGA, J. Una variación anatómica: la desembocadura aberrante del conducto torácico. Biomedica, 2009, vol. 29, n. 29, p. 204-208.

SKANDALAKIS, JE., SKANDALAKIS, LJ. and SKANDALAKIS, PN. Anatomy of the lymphatics. Surgical Oncology Clinics of North America, 2007, vol. 16, n. 1, p. 1-16. http://dx.doi.org/10.1016/j. soc.2006.10.006. PMid:17336233.

TESTUT, L., JACOB, O. and BILLET, H. Précis-atlas de dissection des régions. Paris: Octave Doin, 1921.

Received September 21, 2014 Accepted November 17, 2015 